\title{
Nano Silicon Composite with Gelatin/Melamine Derived N-doped Carbon as an Efficient Anode Material for Li-ion Batteries
}

\author{
Venugopal Nulu* \\ Department of Nanoscience and Engineering, Center for Nano Manufacturing, Inje University, \\ Gyeongnam-do 50834, Republic of Korea
}

\begin{abstract}
Silicon ( $\mathrm{Si}$ ) has a high theoretical capacity and low working potential vs. $\mathrm{Li} / \mathrm{Li}^{+}$, and has been investigated as the most capable negative electrode material for lithium-ion batteries (LIBs). However, Si undergoes significant volume changes during the $\mathrm{Li}^{+}$alloying/ dealloying processes, leading to unstable cycle life and limiting its practical applicability in anodes. Introducing carbon into the Si anodes can effectively address the Si drawbacks, while providing advantages of improved conductivity and structural stability. In this study we choose gelatin/ melamine combination as an eco-friendly and cost-effective source for nitrogendoped carbon to make a Si composite. The prepared composite was studied as an anode material for LIBs, and it delivered excellent cyclability with $2175 \mathrm{mAh} \mathrm{g}^{-1}$ capacity after 50 cycles with 86\% capacity retention at $200 \mathrm{~mA} \mathrm{~g}^{-1}$. The composite exhibited superior rate capability and improved $\mathrm{Li}^{+}$diffusion properties compared with bare Si nanoparticles (Si NP). The significant enhancement could be attributed to the structural stability and conductivity provided by the nitrogen-doped carbon matrix. This work promotes emerging batteries with low-cost materials as a promising solution for increasing energy storage requirements.
\end{abstract}

(Received June 29, 2021; Accepted August 20, 2021)

Keywords: gelatin and melamine, silicon-carbon composite, anode material, li-ion diffusion, li-ion batteries.

\section{Introduction}

The demand for lithium-ion batteries (LIBs) is increasing for applications in electric vehicles (EVs), portable electronic devices, utility power grids, etc., because they provide high energy and power densities, a long stable cycle life, and good safety performance [1-4]. LIBs typically require electrode materials with high theoretical capacities, good conductivity, and high structural stability. Currently, graphite (with a theoretical capacity of $\sim 372 \mathrm{mAh} \mathrm{g}^{-1}$ ) is used as a conventional anode material for LIBs, but has difficulty meeting the high energy and power densities needed for practical applications [5]. For this reason, alternative non-carbonaceous anode materials have been investigated for high-capacity and highperformance LIBs. Among them, Si is currently considered the most suitable anode material because of its high

\footnotetext{
- Venugopal Nulu: 조교수

*Corresponding Author: Venugopal Nulu

[Tel: +82-55-320-3717, E-mail: venungopal@gmail.com, venungopal@inje.ac.kr]

Copyright (c) The Korean Institute of Metals and Materials
}

theoretical capacity of $4200 \mathrm{mAh} \mathrm{g}^{-1}$, which is ten times more than traditional graphite anode. In addition, $\mathrm{Si}$ has a low working potential of around $0.4 \mathrm{~V}$ vs. $\mathrm{Li}^{+} / \mathrm{Li}$, which avoids lithium metal deposition upon overcharge. $\mathrm{Si}$ is also highly abundant in the earth's crust and environmentally benign, which further supports its practical use in high energy/power density applications [6-8]. However, Si experiences large volume changes during the $\mathrm{Li}^{+}$insertion/ extraction process, causing heavy mechanical stress and active material cracking, leading to an unstable solid electrolyte interphase (SEI) leading to rapid capacity fading. The structural destruction of the active material and low intrinsic conductivity further hampers overall battery performance [9-11]. Previous reports have suggested that the internal cracking of electrodes, pulverization of the active material, and ever-growing SEI layer are critical factors that promote battery degradation $[12,13]$.

Different strategies have been developed to address these drawbacks of the Si anodes. Reducing the size of the silicon particles from bulk to nano-size, and creating different nano- 
structures, are reported to be effective ways of controlling the structural and morphological damage, and improving cycling performance [14-17]. Coating the Si particles with carbon, or fabricating $\mathrm{Si} /$ carbon composites, are also prominent strategies for avoiding the drawbacks of bare $\mathrm{Si}$ anode materials. The large buffer volume provided by the carbon in the composite material effectively controls the large volume changes in the $\mathrm{Si}$ during the $\mathrm{Li}^{+}$alloying and dealloying processes. Also, the high electrical conductivity of the carbon matrix improves $\mathrm{Li}^{+}$diffusion properties, by providing more charges during $\mathrm{Li}^{+}$reactions [18-21].

Different types of carbon sources such as polyvinyl pyrrolidone, polyacrylonitrile, and polyvinylidene fluoride have been used as precursors for the carbon coated on $\mathrm{Si}$ particles [22-24]. These chemicals are not eco-friendly and require multi-step synthesis procedures with relatively long reaction times. As a result, there are still challenges to producing Si-carbon composites as functional negative electrode materials for LIBs.

With this perspective, we chose gelatin as a new potential carbon precursor, because of its high carbon composition, non-toxicity, bio-compatibility, and low cost [25]. Limited research has been performed using gelatin as a carbon source. In a previous report, Ulfa et al. prepared mesoporous carbon with a high specific surface area from gelatin as the source of carbon using a hard template technique [26]. Jiang et al. reported an $\mathrm{Si}$ anode modified with carbonized gelatin binder, which demonstrated good electrochemical performance by providing uniform dispersion of the Si particles in the carbon matrix. The composite delivered $990.3 \mathrm{mAh} \mathrm{g}^{-1}$, at $100 \mathrm{~mA}$ $\mathrm{g}^{-1}$ after 70 cycles.

It is also evident that nitrogen $(\mathrm{N})$ doping of the carbon material can significantly increase its electrical conductivity, which is highly beneficial for long cycle life and superior rate performance [27,28]. For $\mathrm{N}$ doping we selected melamine, which is a good source of $\mathrm{N}$, with non-toxicity and low cost [29].

Inspired by these findings, we prepared uniformly carboncoated Si NPs using a simple two-step approach. To form a uniform coating on the Si particles, firstly, we modified the surface of the Si particle with citric acid as the modifying agent, because it has multiple functional groups (-COOH, $-\mathrm{OH})$ which can ensure strong interactions with the Si NP. So, that it can form an active surface after modification by forming silyl esters (-Si-O-C(O)-C-) as per previous reports [30,31,32]. Later we used the gelatin/melamine combination to form an organic layer, firmly attached on the Si's surface by bonding with silyl groups. High-temperature carbonization was used to make the N-doped carbon coating on the Si's surface. The prepared hybrid $\mathrm{Si} /$ carbon composite was investigated as an anode for LIBs, and it showed excellent electrochemical properties, which were attributed to the synergetic effects of the $\mathrm{Si}$ and $\mathrm{N}$-doped carbon matrix.

\section{Experimental Procedures}

\subsection{Materials and methods}

\subsubsection{Materials}

Silicon powder, crystalline (Alfa Aesar, $\leq 50 \mathrm{~nm}$ ), citric acid (ACS reagent, $\geq 99.5 \%$ ), gelatin (Sigma-Aldrich), melamine (99\% Sigma-Aldrich), TIMCAL Graphite \& Carbon black (Super-P ${ }^{\circledR}$ ) (MTI Korea), 1-methyl-2-pyrrolidinone (NMP, ReagentPlus $^{\circledR}$, 99\%), acetone (Sigma Aldrich, $\geq 99.5 \%$ ), polyamide-imide (PAI) (Torlon $^{\circledR}$ ) were purchased and used without further purification.

\subsubsection{Preparation for surface modification of the Si NPs}

Surface modification of Si NPs was carried out using citric acid in an NMP solution, following previously reported methods [33]. Firstly, 20\% of citric acid was dissolved in the NMP solution and stirred for $30 \mathrm{~m}$. Then $500 \mathrm{mg}$ of Si NP was added to the solution and sonication carried out for $1 \mathrm{~h}$ to form a uniform mixture. Then the mixture was stirred for $6 \mathrm{~h}$, and every $30 \mathrm{~min}$ the sample was sonicated to avoid particle aggregation, a total of five times. Later, the Si NPs were separated by centrifugation and washed several times with NMP followed by acetone to remove unreacted citric acid and residual NMP, respectively. The samples were airdried and transferred to a vacuum oven at $40{ }^{\circ} \mathrm{C}$ for $12 \mathrm{~h}$. The same procedure was repeated to complete surface modification of the Si NPs, which were subsequently named MSi. A simplified diagram of the surface modification process of the Si NPs is shown in Fig. 1(a).

\subsubsection{Preparation of $\mathrm{N}$-doped carbon-coated $\mathrm{Si}$}


(a)
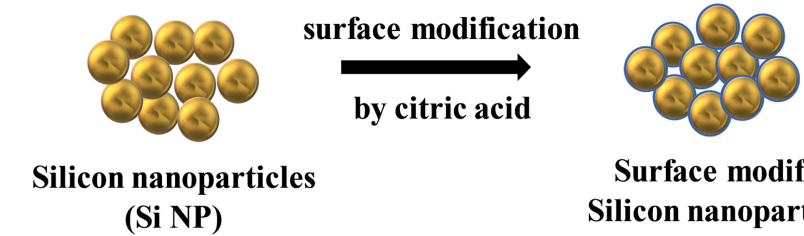

Surface modified

Silicon nanoparticles

(MSi)

(b)

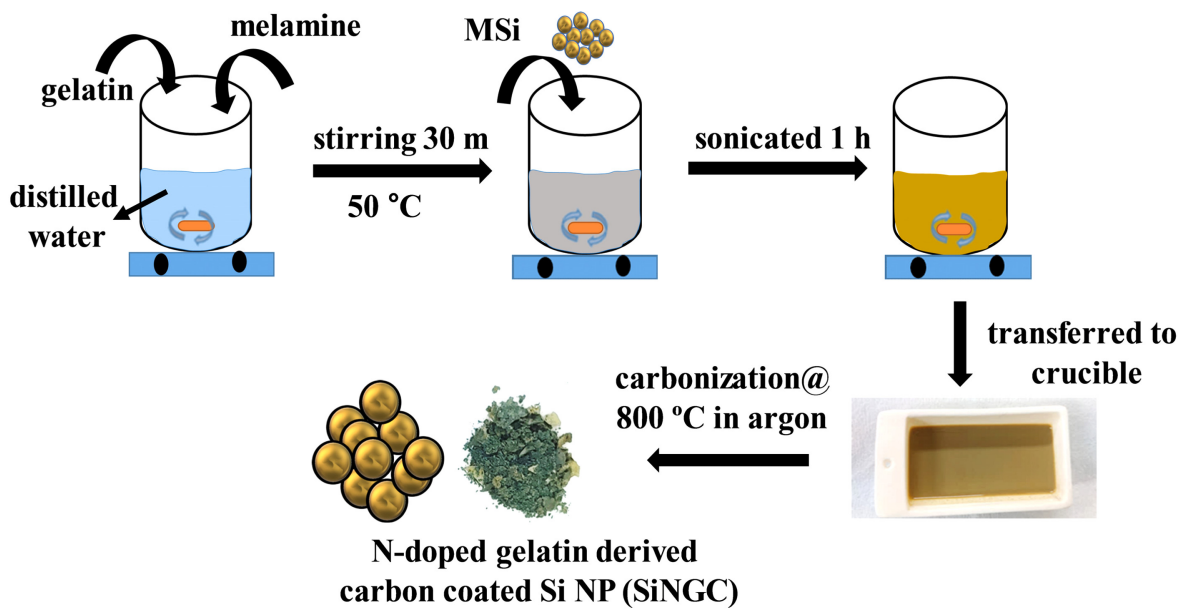

Fig. 1. (a) Process of silicon nanoparticles surface modification by citric acid (b) Step by step fabrication process of the SiNGC composite.

NPs

The step-by-step preparation process of the N-doped carbon-coated Si NPs is shown in Fig. 1(b). As shown in Fig. (b), $200 \mathrm{mg}$ of gelatin and $400 \mathrm{mg}$ of melamine were dissolved in $30 \mathrm{ml}$ of distilled water at $50{ }^{\circ} \mathrm{C}$ by magnetic stirring to make a uniform solution. Then $400 \mathrm{mg}$ of $\mathrm{MSi}$ particles were added to the solution, and magnetic stirring continued for $1 \mathrm{~h}$. Then the jelly-like mixture was carefully transferred to an alumina crucible. The crucible was placed in a tubular furnace and carbonized at $800{ }^{\circ} \mathrm{C}$ for $2 \mathrm{~h}$ in an argon atmosphere at a heating rate of $5{ }^{\circ} \mathrm{C}$ per minute. After the furnace was allowed to reach room temperature, the product, named SiNGC, was collected and used for further analysis.

\subsection{Chemical Analysis and Characterization} Techniques

The crystallographic structure of the prepared material was determined by X-ray diffraction (XRD), in the range of $10^{\circ}$ $<2 \theta<80^{\circ}$. Raman spectroscopy was used to analyze the carbon in the prepared composite. The surface composition of the sample was investigated by X-ray photoelectron spectroscopy (XPS). The surface morphologies of the materials were surveyed by scanning electron microscopy (SEM) and transmission electron microscopy (TEM). Thermogravimetric analysis (TGA) data were recorded at 50$800{ }^{\circ} \mathrm{C}$, with a $10{ }^{\circ} \mathrm{C} \mathrm{min}^{-1}$ heating rate, under air atmosphere.

\subsection{Electrochemical Analysis}

All the electrochemical measurements were evaluated using 2032R button-type coin cells. The working electrodes were prepared with $70 \mathrm{wt} \%$ of the prepared electrode material and $20 \mathrm{wt} \%$ super $\mathrm{P}$ carbon as a conductive additive and $10 \mathrm{wt} \%$ polyamide-imide in $\mathrm{N}$-methyl pyrrolidone (NMP) as a binder. All of the added components were well mixed using a mini-mill for 30 min to make a homogeneous slurry. The resulting slurry was uniformly cast on a copper foil using the traditional doctor blade method. The electrode was dried at $80^{\circ} \mathrm{C}$ for two hours to evaporate NMP. The dry electrode was placed in a vacuum oven and treated at $200{ }^{\circ} \mathrm{C}$ for $3 \mathrm{~h}$ to activate the binder. A bare $\mathrm{Si}$ nanoparticles ( $\mathrm{Si}$ NPs) electrode was separately prepared under the same conditions to compare with the SiNGC composite electrode. All of the prepared electrodes were punched with a diameter of $14 \mathrm{~mm}$. The calculated mass loading of the active material 
on the copper foil was $\sim 1.2 \mathrm{mg} \mathrm{cm}^{-2}$. All cells were fabricated in a glove box filled with argon gas, using metallic Li as the counter electrode, polypropylene membrane as the separator, and standard $1 \mathrm{M} \mathrm{LiPF} 6$ in ethylene carbonate, diethyl carbonate, and fluoroethylene carbonate with a v/v ratio of 5:70:25 as an electrolyte.

All cells were examined in the voltage range of $0.01 \mathrm{~V}-2.0 \mathrm{~V}$ vs. $\mathrm{Li} / \mathrm{Li}^{+}$at an applied current density of $200 \mathrm{~mA} \mathrm{~g}^{-1}$. The rate capability tests were performed with a wide range of current densities (100-3200 $\left.\mathrm{mA} \mathrm{g}^{-1}\right)$. The redox behavior was analyzed using cyclic voltammetry $(\mathrm{CV})$ in the same voltage range at a $0.1 \mathrm{mV} \mathrm{s}^{-1}$ scan rate. Electrochemical impedance spectroscopy (EIS) studies were performed in the frequency range of $10 \mathrm{mHz}-10 \mathrm{kHz}$ and the amplitude was $5 \mathrm{~mA}$ to evaluate reaction kinetics of the composite material. The specific capacities of all cells were calculated based on the active material's weight.

\section{Results and Discussion}

Fig. 2(a) shows the measured XRD patterns of the prepared Si NP and SiNGC electrode materials. Prominent diffraction peaks of the SiNGC composite appeared at $2 \theta=28.4^{\circ}, 47.4^{\circ}$, $56.2^{\circ}, 69.2^{\circ}$ and $79.5^{\circ}$ (JCPDS\#27- 1402), corresponding to the (111), (220), (311), (400), and (331) lattice planes of crystalline $\mathrm{Si}$, resulting from the well retained crystalline nature of the $\mathrm{Si}$ in the composite after high-temperature heat treatment. The broad peak between $2 \theta=20^{\circ}$ to $25^{\circ}$ corresponds to the characteristic peaks of amorphous carbon derived from the carbonization of the gelatin/melamine and the $\mathrm{SiO}_{\mathrm{x}}$ layer. $\mathrm{SiO}_{\mathrm{x}}$ can form during the carbonization process because of the highly reactive surface of the Si NPs [20,34].
The carbon content in the prepared SiNGC composite was analyzed by Raman spectra within the range of $200-1200 \mathrm{~cm}^{-1}$ at room temperature, and the resulting plot was compared with the spectra of pristine Si NPs, and depicted in Fig. 2(b). From the figure, both samples exhibited characteristic peaks of $\mathrm{Si}$ at $508 \mathrm{~cm}^{-1}$ and $927 \mathrm{~cm}^{-1}$, resulting from the crystal structure of the $\mathrm{Si}$. The two broad peaks that appeared at $1344 \mathrm{~cm}^{-1}$ and $1588 \mathrm{~cm}^{-1}$ in the SiNGC correspond to the D-band and G-band, resulting from structural defects and graphitic carbon respectively, indicating the successful formation of carbon from gelatin [35]. The characteristics of the carbon formed in the sample can be determined by the intensity ratio of the $\mathrm{D}$ and $\mathrm{G}$ bands $\left(\mathrm{I}_{\mathrm{D}} / \mathrm{I}_{\mathrm{G}}\right)$. From the data, the calculated ratio of $\mathrm{I}_{\mathrm{D}} / \mathrm{I}_{\mathrm{G}}$ was 0.954 , demonstrating that the gelatinderived carbon has good graphitic characteristics, providing excellent electric conductivity and required buffer volume to the $\mathrm{Si}$ during the $\mathrm{Li}^{+}$reactions. The increased conductivity in the composite material can also have a positive effect on the $\mathrm{Li}^{+}$kinetics in the electrode material, and eventually deliver improved electrochemical properties.

The amount of carbon in the prepared composite material was analyzed using TGA from $50{ }^{\circ} \mathrm{C}$ to $800^{\circ} \mathrm{C}$ at a heating rate of $10{ }^{\circ} \mathrm{C} \mathrm{min}-1$ in an air atmosphere, and the resulting plot is displayed in Fig. 2(c). For the bare Si NPs, above $500{ }^{\circ} \mathrm{C}$, a steady increase in weight was observed, indicating the formation $\mathrm{SiO}_{\mathrm{x}}$ due to the partial oxidation of the Si NPs [34]. The calculated weight loss of the prepared SiNGC composite was $13 \%$. This weight loss can be attributed to the oxidation of carbon in the air atmosphere.

The surface chemical composition of the sample was investigated with XPS, and the results are shown in Fig 3. The wide survey scan spectrum is displayed in Fig. 3(a), indicating that the composite material is a combination of $\mathrm{Si}$,
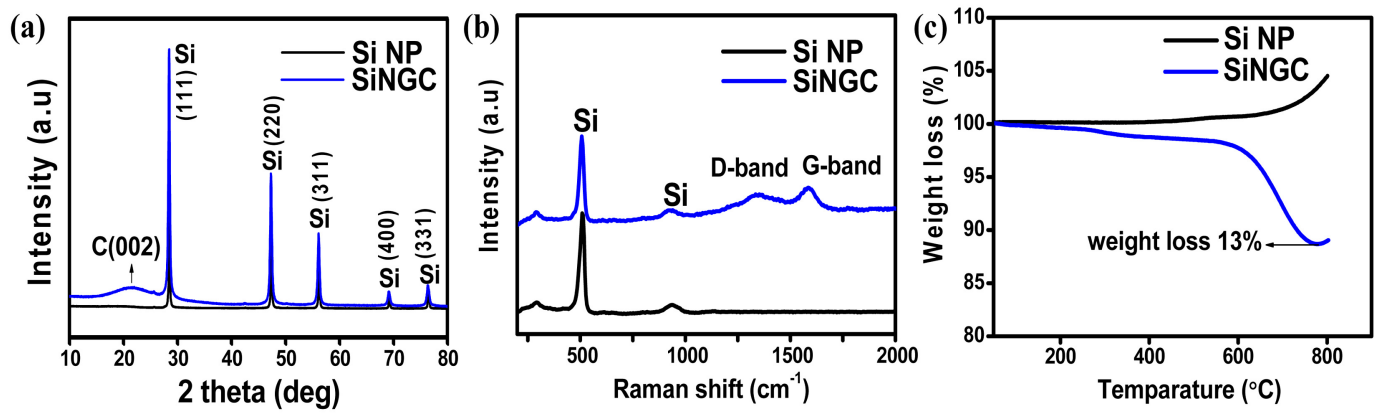

Fig. 2. (a) XRD patterns (b) Raman spectra (c) and Thermogravimetric results of bare Si and the SiNGC composite. 
(a)

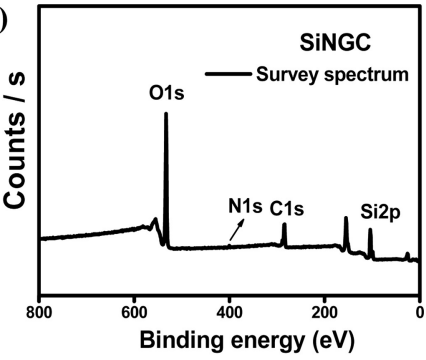

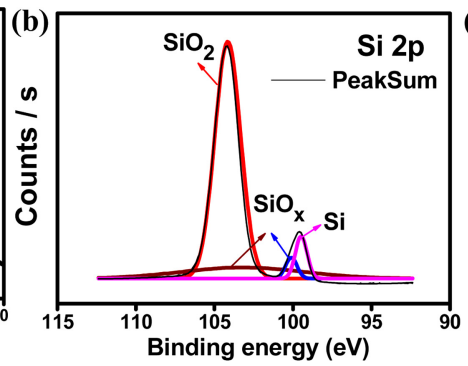

(e)
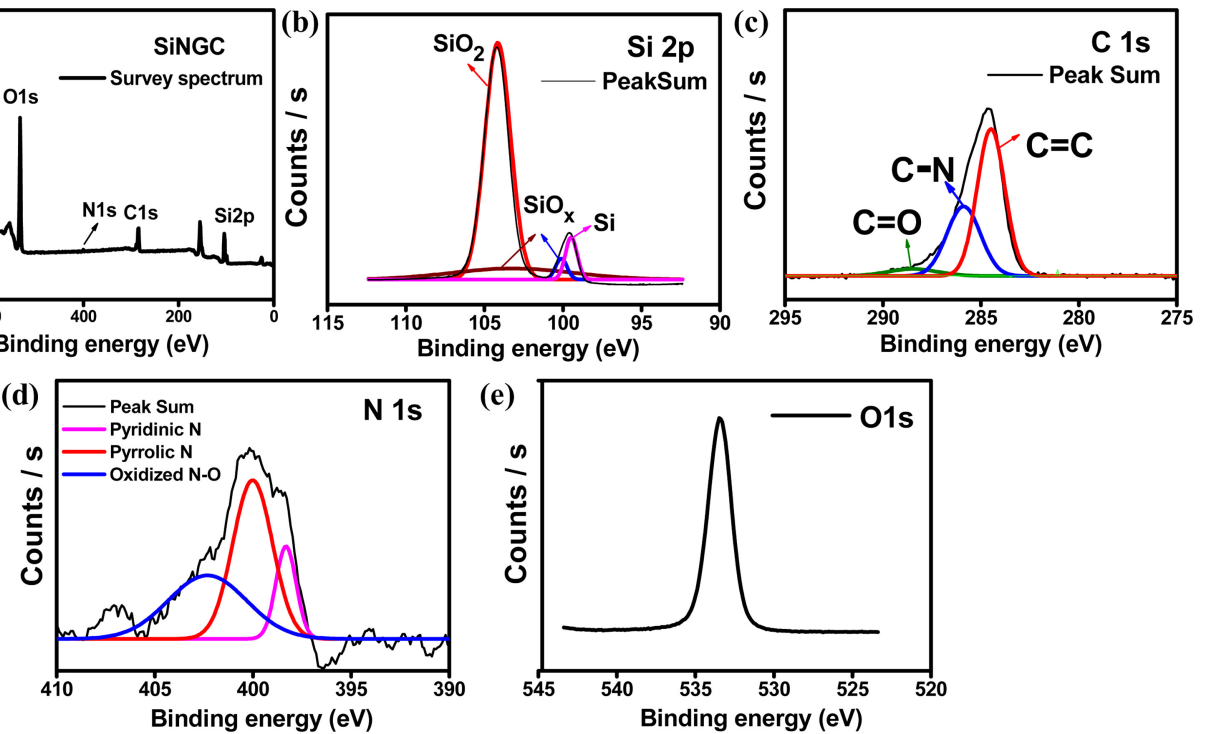

Fig. 3. XPS spectra of the SiNGC composite (a) survey spectra (b) Si 2p (c)C1s (d) N1s (e) O1s.

$\mathrm{C}, \mathrm{N}$, and $\mathrm{O}$ [36]. The curve fitting approach was used to distinguish the chemical states of $\mathrm{Si}, \mathrm{C}$, and $\mathrm{N}$. The highresolution Si 2p spectra are depicted in Fig. 3(b). The figure shows that the peaks at binding energies of $99.4 \mathrm{eV}$ and $104 \mathrm{eV}$ correspond to the $\mathrm{Si}$ and $\mathrm{SiO}_{2}$, respectively. The peaks from $99-104 \mathrm{eV}$ are related to the $\mathrm{SiO}_{\mathrm{x}}(1<\mathrm{x}<2)$ layer, indicating the formation of $\mathrm{SiO}_{\mathrm{x}}$ due to the partial surface oxidation of the Si particles [34]. The high-resolution spectra of the $\mathrm{C} 1 \mathrm{~s}$ can be fitted into three peaks, which are shown in Fig. 3(c). The peak at a binding energy at $284.4 \mathrm{eV}$ is related to $\mathrm{C}=\mathrm{C}$, and the peaks at $285.8 \mathrm{eV}$ and $288.2 \mathrm{eV}$ correspond to $\mathrm{C}-\mathrm{N}$ and $\mathrm{C}=\mathrm{O}$, respectively [37].

In Fig. 3(d), the high-resolution N1s spectra is fitted into three peaks at binding energies of $398.2 \mathrm{eV}, 400 \mathrm{eV}$, and $401.8 \mathrm{eV}$, attributed to pyridinic-N, pyrrolic-N, and oxidized$\mathrm{N}$, respectively [38]. The existence of $\mathrm{N}$ in the composite indicates $\mathrm{N}$ was successfully doped into the carbon, which can significantly increase the conductivity of the composite SiNGC and improve the electrochemical performance of the electrode material. In Fig. 3(e) the peak at a binding energy at $533 \mathrm{eV}$ corresponds to oxygen from the $\mathrm{SiO}_{\mathrm{x}}$ oxidation layer.

SEM and TEM were employed to determine the surface morphologies of the prepared composite material. The SEM images of the SiNGC sample are shown in Fig. (4). From the images in Fig. 4(a) and Fig. 4(b), it is evident that the Si NPs

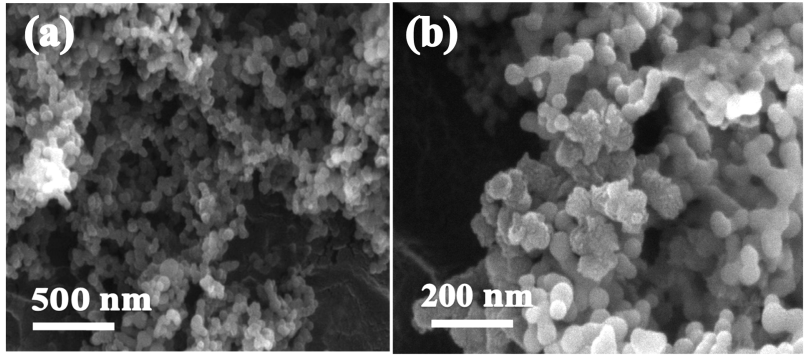

Fig. 4. (a) \& (b) SEM images of the SiNGC material at different magnifications.

have an aggregated morphology. TEM images of the SiGNC composite at different magnifications are shown in Fig. 5. From Fig. 5(a) and (b), it is clear that the Si NPs are embedded in the carbon matrix, and that most of the Si NPs are coated with carbon.

The high-resolution TEM (HR-TEM) image of the carboncoated Si NP from Fig. 5(b) (black box) is shown in Fig. 5(c), and it exhibits a crystalline characteristic, with $0.31 \mathrm{~nm} \mathrm{~d}$ spacing corresponding to the $\mathrm{Si}$ (111) plane. The carboncoated outer layer is indicated by the black arrow. Fig. 5(d) depicts the energy-dispersive X-ray elemental studies (EDX) of the SiNGC composite material, corresponding to $\mathrm{Si}, \mathrm{C}, \mathrm{N}$, and $\mathrm{O}$, respectively. From the EDX results, it is evident that the Si NPs are surrounded by an N-doped carbon matrix. All of these findings are in good agreement with the XRD and Raman spectra results. 


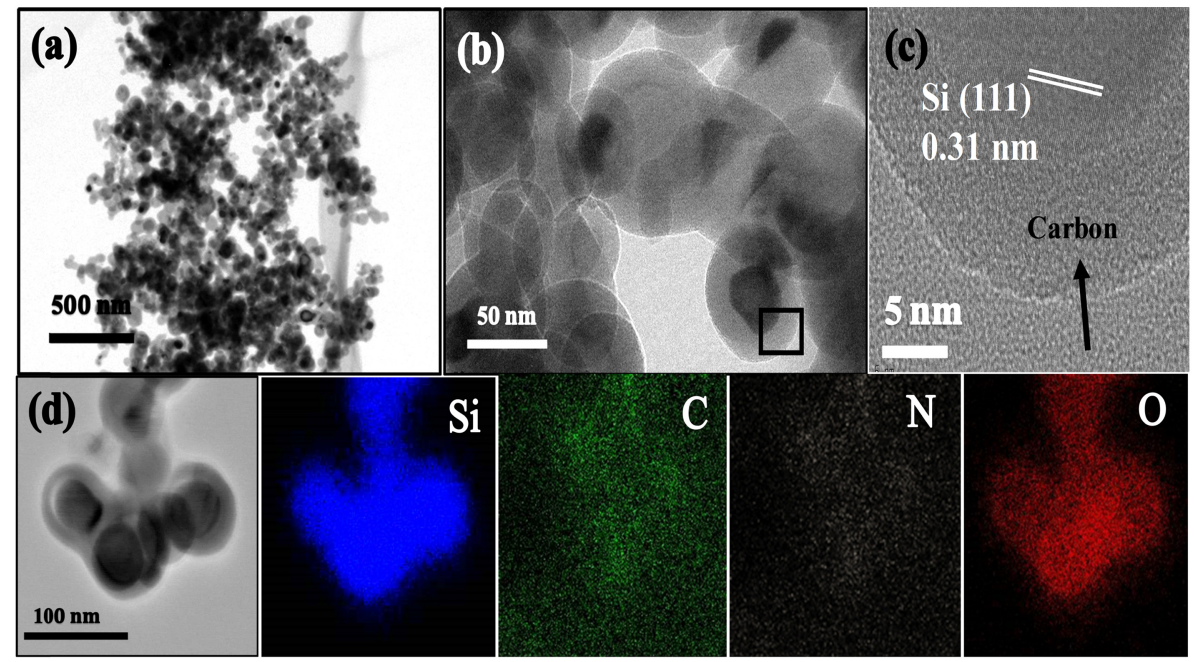

Fig. 5. (a) \& (b) TEM images, (c) HR-TEM image of the SiNGC composite. (d) TEM image and corresponding elemental mapping of the SiNGC composite.

Several electrochemical tests were carried to evaluate the performance of the prepared SINGC composite electrode as an anode material for LIBs. CV was performed to analyze the redox behavior of the prepared electrodes, the bare Si NPs, and the SiNGC electrodes at $0.1 \mathrm{mV} \mathrm{s}^{-1}$ between $0.01 \mathrm{~V}-2.0$ $\mathrm{V}$, and the resulting voltage vs. current plots for the first five cycles are displayed in Fig. 6(a) and 6(b) respectively.

For the bare Si NPs, the first cathodic scan shows a broad peak from $1.2 \mathrm{~V}-0.4 \mathrm{~V}$, resulting from the decomposition reaction of the electrolyte and the formation of the SEI layer. In the SiNGC electrode, the typical broad peak appeared at around $\sim 0.56 \mathrm{~V}$, representing the large SEI formation. The possible reason could be the availability of a large surface area of the prepared electrode material in the $\mathrm{N}$-doped carbon matrix. A large electrolyte/electrode interfacial area can encourage the electrolyte decomposition reaction and lead to larger SEI formation. These broad peaks disappeared in the following cycles for both electrodes, indicating stable SEI formation. The peaks at $0.14 \mathrm{~V}, 0.05 \mathrm{~V}$ vs. $\mathrm{Li}^{+} / \mathrm{Li}$ for $\mathrm{Si} \mathrm{NPs}$, and $0.19 \mathrm{~V}$ and $0.05 \mathrm{~V}$ vs. $\mathrm{Li}^{+} / \mathrm{Li}$ for the SiNGC electrodes represent the alloying reaction of $\mathrm{Li}^{+}$into the active material and the formation of a metastable amorphous $\mathrm{Li}_{\mathrm{x}} \mathrm{Si}$ phase [20].

In an anodic scan, the peaks at $0.38 \mathrm{~V}$ and $0.55 \mathrm{~V}_{\text {vs. }} \mathrm{Li}^{+} /$ $\mathrm{Li}$ in SiNGC are correlated to the two-step dealloying reaction of $\mathrm{Li}^{+}$from the $\mathrm{Li}_{x} \mathrm{Si}$ phase and the formation of amorphous Si. On the other hand, only one peak at $0.53 \mathrm{~V}$ vs.
$\mathrm{Li}^{+} / \mathrm{Li}$ appeared for the $\mathrm{Si} \mathrm{NPs}$, indicating a slow and sluggish dealloying process.

Compared with the Si NPs, the overall CV profile of the SiNGC was little changed, and the peak intensities decreased, which could be due to the presence of the carbon matrix. For both electrodes, the peak intensities gradually increased with the number of cycles, indicating the activation process of the active materials, a characteristic phenomenon observed in Sibased anode materials [19-21]. The voltage vs. specific capacity plots of the SiNGC electrode for the $1^{\text {st }}, 2^{\text {nd }}$, and $50^{\text {th }}$ cycles at an applied current density $200 \mathrm{~mA} \mathrm{~g}^{-1}$ are depicted in Fig. 6(c). As shown in the plots, the long discharge plateaus between $0.2 \mathrm{~V}-0.01 \mathrm{~V}$ correspond to the characteristic alloying process of $\mathrm{Li}^{+}$-ions into $\mathrm{Si}$ particles, and the formation of the $\mathrm{Li}_{\mathrm{X}} \mathrm{Si}$ phase. During charging, the voltage plateaus between $0.2 \mathrm{~V}-0.62 \mathrm{~V}$ correspond to the dealloying process of $\mathrm{Li}^{+}$ions from $\mathrm{Si}$ and indicate the formation of amorphous Si. After the first cycle, the discharge plateaus shifted to $0.25 \mathrm{~V}$ due to the typical transformation of crystalline Si into amorphous Si [39].

The cycling performance of the prepared SiNGC composite was evaluated at an applied current density of $200 \mathrm{~mA} \mathrm{~g}^{-1}$ for 50 cycles and compared with the performance of the bare $\mathrm{Si}$ NPs. The resulting specific capacity vs. cycle number plots is shown in Fig. 6(d). In the first cycle, the Si NPs exhibited specific capacities of $3772 / 3010 \mathrm{mAh} \mathrm{g}^{-1}$ with $79 \%$ of initial coulombic efficiency (ICE). The irreversible capacity loss of 

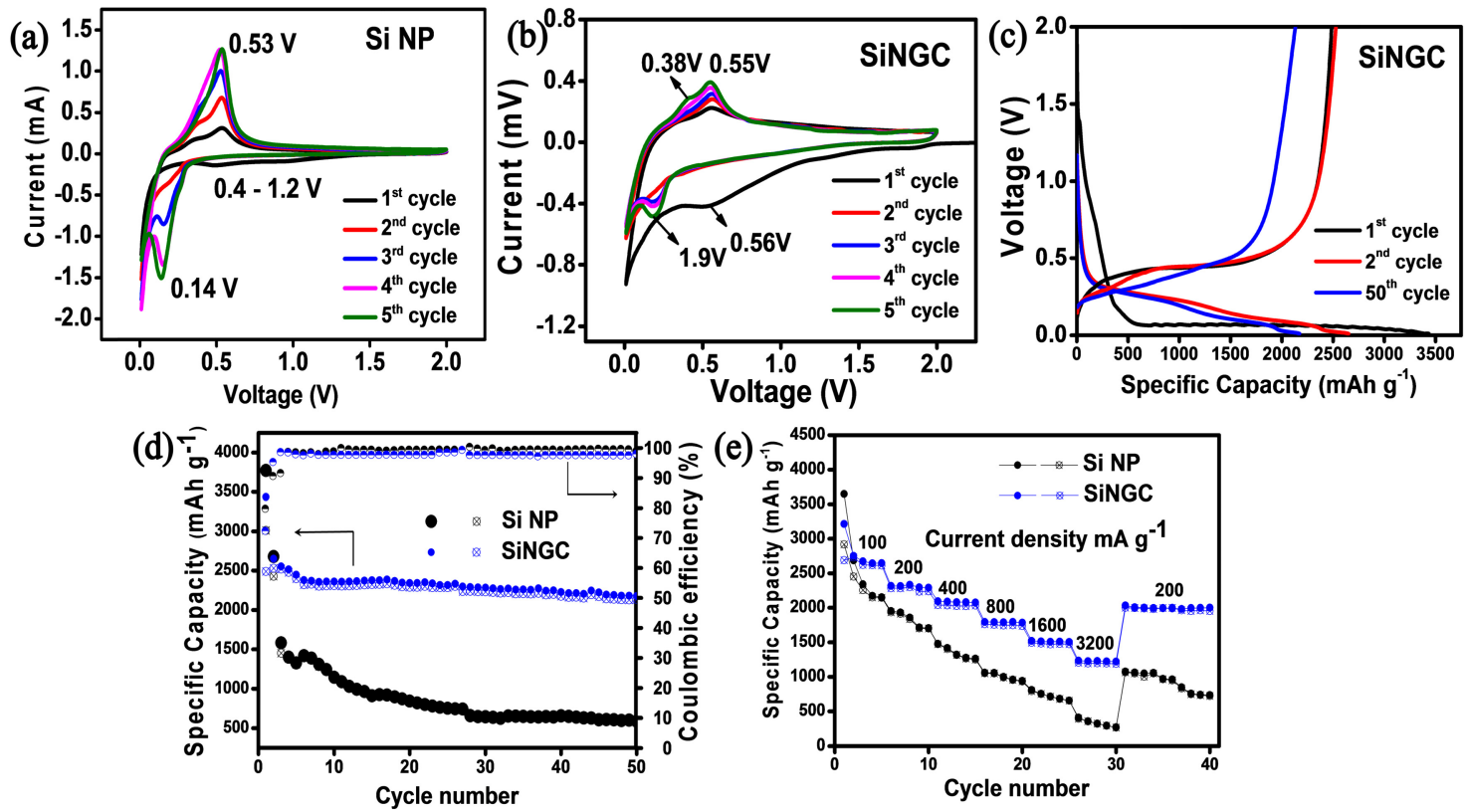

Fig. 6. Cyclic voltammograms of (a) bare Si (b) the SiNGC composite. (c) Charge-discharge voltage profiles of the SiNGC composite. (d) Cyclability with coulombic efficiency, (e) rate capability results of the bare $\mathrm{Si}$ and SiNGC composite.

$762 \mathrm{mAh} \mathrm{g}^{-1}$ can be attributed to the formation of the SEI layer on the electrode's surface. After 50 cycles, the electrode reached 586/579 $\mathrm{mAh} \mathrm{g}^{-1}$ specific capacities with 99\% CE. The rapid capacity loss in the Si NPs is related to the large volume changes in the active material with the $\mathrm{Li}^{+}$reactions, which causes the active material to lose contact with the current collector.

On the other hand, the prepared SiNGC electrode showed initial capacities of 3434/2488 $\mathrm{mAh} \mathrm{g}^{-1}$ with an ICE of $72 \%$ with $946 \mathrm{mAh} \mathrm{g}^{-1}$ irreversible capacity loss. The lower CE/ more irreversible capacity loss in the SiNGC electrode is caused by the formation of a larger SEI layer (see Fig. 6(b)), which consumes a large amount of $\mathrm{Li}^{+}$ions due to the large surface reaction area afforded by the $\mathrm{N}$-doped carbon matrix [40]. At the 2nd cycle, the composite electrode exhibited a coulombic efficiency of $95 \%$ with specific capacities of $2651 / 2528 \mathrm{mAh} \mathrm{g}^{-1}$. This greater enhancement in coulombic efficiency indicates the formation of a stable SEI layer. After the $50^{\text {th }}$ cycle, the SiNGC electrode delivered $2175 / 2132$ $\mathrm{mAh} \mathrm{g}^{-1}$ specific capacities with $85.7 \%$ capacity retention and $98 \%$ of coulombic efficiency, which is excellent reversibility. This performance can be attributed to the highly conductive, structurally stable $\mathrm{N}$-doped gelatin-derived carbon matrix in the composite material.
Rate performance tests were carried out for the Si NPs and the SiNGC electrodes at applied current densities from 100$3200 \mathrm{~mA} \mathrm{~g}^{-1}$ and then compared with those for the bare $\mathrm{Si}$ NPs. The resulting rate performance plots are displayed in Fig. 6(e). The results show that the SiNGC electrode exhibited superior rate capability compared with the bare $\mathrm{Si}$ NPs. The SiNGC electrode delivered 3215, 2316,2093, 1795, 1523 and $1236 \mathrm{mAh} \mathrm{g}^{-1}$ capacities at applied currents of 100 , $200,400,800,1600,3200 \mathrm{~mA} \mathrm{~g}^{-1}$, respectively. After applying a high current density of $3200 \mathrm{mAg}^{-1}$, the composite electrode retained the capacity of $2032 \mathrm{mAh} \mathrm{g}^{-1}$ at $200 \mathrm{~mA} \mathrm{~g}^{-1}$, which is fivefold greater than the commercial graphite anode.

But, the Si NPs electrode delivered $410 \mathrm{mAh} \mathrm{g}^{-1}$ capacity, much less than that of the SiNGC electrode. The rate capability results demonstrate that the excellent conductivity, structural stability, and buffer volume afforded by the Ndoped carbon matrix derived from the gelatin/melamine combination played a key role in suppressing the $\mathrm{Si}$ anode's drawbacks, even at high applied current densities [20,21].

To investigate the $\mathrm{Li}+$ kinetic properties of the prepared electrodes, EIS was employed in the frequency range of $10 \mathrm{mHz}-10 \mathrm{kHz}$, with a $5 \mathrm{~mA}$ amplitude. After 10 cycles at $500 \mathrm{~mA} \mathrm{~g}^{-1}$ current density, EIS was measured, and the resultant plots are shown in Fig. 7(a). As shown in the figure, 

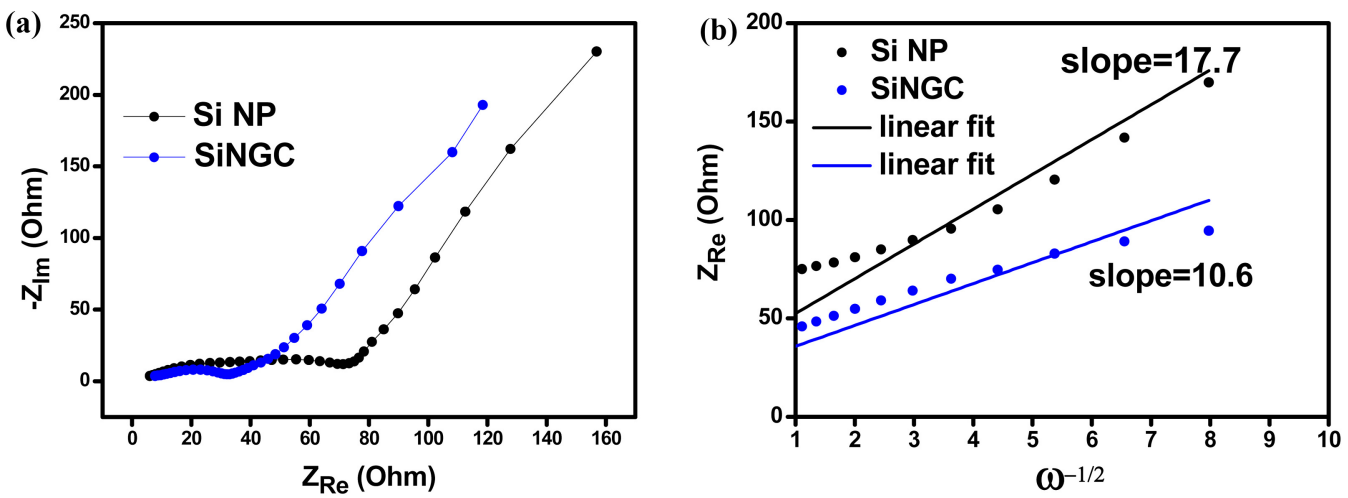

Fig. 7. (a) Nyquist plots of bare Si and the SiNGC composite after 10 cycles at $500 \mathrm{~mA} \mathrm{~g}^{-1}$ (b) fitting results of the $Z_{\mathrm{Re}}$ versus $\omega^{-1 / 2}$ plots of the bare Si and SiNGC composite.

both electrodes exhibited a depressed semicircle from the high to the middle-frequency region, associated with charge transfer resistance at the electrode/electrolyte interface. An inclined straight line in the low-frequency region was assigned to the $\mathrm{Li}^{+}$diffusion kinetics [41,42]. From Fig. 7(a), the diameter of the semicircle for SiNGC is much smaller than that of the Si NPs, indicating lower charge transfer impedance and electron resistance. The SiNGC electrode exhibit solution resistance $\left(R_{s}\right)$ was $3.69 \Omega$ and the charge transfer resistance $\left(\mathrm{R}_{\mathrm{ct}}\right)$ was $33.6 \Omega$, while the base Si Nps exhibited an $\mathrm{R}_{\mathrm{s}}$ of $5.97 \Omega$ and $\mathrm{R}_{\mathrm{ct}}$ of $73.3 \Omega$. These results demonstrate that the coated $\mathrm{N}$-carbon matrix successfully provided the required ionic and ionic channels for faster $\mathrm{Li}^{+}$ kinetics during the $\mathrm{Li}^{+}$insertion/extraction processes, and improved the diffusion properties. The $Z_{\mathrm{Re}}$ vs. $\omega^{-1 / 2}$ plots of both the Si NPs and SiNGC composite electrodes are shown in Fig. $7\left(\right.$ b), where $Z_{\mathrm{Re}}$ linearly depends on $\omega^{-1 / 2}$ in the lowfrequency region. The following equations were used to evaluate the $\mathrm{Li}^{+}$diffusion coefficient (D).

$$
\begin{aligned}
& Z_{R e}=R_{s}+R_{c t}+\sigma_{w} \omega^{-1 / 2} \\
& D=R^{2} T^{2} / 2 A^{2} F^{4} C^{2} \sigma_{w}{ }^{2}
\end{aligned}
$$

Here, $\mathrm{R}$ is the gas constant, $\mathrm{T}$ is the absolute temperature, $\mathrm{C}$ is the $\mathrm{Li}^{+}$ion molar concentration, $\mathrm{A}$ is the electrode area, and $\mathrm{F}$ is the Faraday constant. The Warburg impedance coefficient $\left(\sigma_{\mathrm{w}}\right)$ can be calculated from the slope of $Z_{\mathrm{Re}}$ vs. $\omega^{-1 / 2}$ plots. The calculated Warburg factors for the Si NPs and SiNGC composite were $17.7 \Omega \mathrm{s}^{-1 / 2}$ and $10.6 \Omega \mathrm{s}^{-1 / 2}$, respectively.
As shown in equation (2), the $\mathrm{Li}^{+}$diffusion coefficient is inversely proportional to $\sigma_{\mathrm{w}}$, so that the lower $\sigma_{\mathrm{w}}$ gives a higher diffusion coefficient and favors higher energy densities. The calculated D for the Si NPs and SiNGC electrodes was $9.64 \times 10^{-12} \mathrm{~cm}^{2} \mathrm{~s}^{-1}$ and $2.69 \times 10^{-11} \mathrm{~cm}^{2} \mathrm{~s}^{-1}$, respectively. The higher $\mathrm{D}$ value indicated faster kinetics in the cell reactions in the SiNGC electrode, due to high conductivity and shorter $\mathrm{Li}^{+}$and electron transporting lengths, resulting from the $\mathrm{N}$-doped carbon matrix.

Finally, the surface-modified Si NPs provide a successful platform for a firm, uniform coating of the N-doped carbon matrix derived from an eco-friendly gelatin/melamine combo. The synergetic effect of the high capacity $\mathrm{Si}$ anode and highly conductive and flexible N-doped carbon matrix significantly improves electrochemical properties, delivers highly stable cycle life, and is advantageous for the low-cost preparation of high energy anode materials for practical LIB applications. We have compared the applied current density, specific capacity, and capacity retention percentages of different $\mathrm{Si} /$ carbon composites and summarized them in Table 1.

\section{Conclusion}

In summary, we prepared Si nanoparticles firmly coated with a nitrogen-doped carbon matrix using a simple two-step approach. Surface modification with citric acid creates an active surface on the Si NPs, which allowed the particles to bond to the gelatin/melamine combination. A subsequent high-temperature heat treatment resulted in $\mathrm{Si}$ particles 
Table 1. Comparison of silicon/carbon composite materials and their electrochemical performances

\begin{tabular}{|c|c|c|c|c|c|}
\hline Materials & Synthetic method & Structure & $\begin{array}{l}\text { Initial } \\
\mathrm{CE} \%\end{array}$ & $\begin{array}{l}\text { Anode performance } \\
\text { (capacity retention \%) }\end{array}$ & Ref. \\
\hline Si nanospheres/acetylene & $\begin{array}{c}\text { Magnesiothermic reduction } \\
\text { and CVD }\end{array}$ & Core-shell & $71.3 \%$ & $\begin{array}{c}3207 \mathrm{mAh} \mathrm{g}^{-1} \text { after } 100 \text { cycles } \\
\text { at } \mathrm{C} / 20(85 \%)\end{array}$ & 43 \\
\hline Si microspheres/acetylene & $\begin{array}{l}\text { Modified template } \\
\text { methods and CVD }\end{array}$ & Yolk-shell & $80 \%$ & $\begin{array}{c}1100 \mathrm{mAh} \mathrm{g}^{-1} \text { after } 200 \text { cycles } \\
\text { at } 250 \mathrm{mAg}^{-1}\end{array}$ & 44 \\
\hline Si nanoparticles/polystyrene & $\begin{array}{l}\text { Sol-gel methods and } \\
\text { carbonization }\end{array}$ & Yolk-shell & $43 \%$ & $\begin{array}{c}740 \mathrm{mAh} \mathrm{g}^{-1} \text { after } 200 \\
\text { cycles at } \mathrm{C} / 10\end{array}$ & 45 \\
\hline $\begin{array}{l}\text { Si nanoparticles/white } \\
\text { wheat flour }\end{array}$ & $\begin{array}{l}\text { Ball milling and } \\
\text { annealing }\end{array}$ & Core-shell & $71 \%$ & $\begin{array}{l}880 \mathrm{mAh} \mathrm{g}^{-1} \text { after } 90 \\
\text { cycles at } \mathrm{C} / 20(92 \%)\end{array}$ & 46 \\
\hline Micronized Si/citric acid & $\begin{array}{l}\text { Ball milling and } \\
\text { carbonization }\end{array}$ & Core-shell & & $\begin{array}{l}850 \mathrm{mAh} \mathrm{g}^{-1} \text { after } 106 \\
\text { cycles at } \mathrm{C} / 20\end{array}$ & 47 \\
\hline Si nanospheres/propylene & $\begin{array}{l}\text { Thermal decomposition } \\
\text { and laser ablation } \\
\text { processing }\end{array}$ & Core-shell & $94 \%$ & $\begin{array}{l}1200 \mathrm{mAh} \mathrm{g}^{-1} \text { after } 300 \\
\text { cycles at } 0.2 \mathrm{~A} \mathrm{~g}^{-1}\end{array}$ & 48 \\
\hline $\begin{array}{l}\text { Silicon@porous nitrogen-doped } \\
\text { carbon spheres }\end{array}$ & bottom-up approach & $\begin{array}{l}\text { Si particles embedded } \\
\text { the carbon sphere }\end{array}$ & $42 \%$ & $\begin{array}{c}1579 \text { mAh g-1 after } 300 \\
\text { cycles at C/10 (94\%) }\end{array}$ & 49 \\
\hline $\begin{array}{l}\text { Nitrogen-rich carbon/silicon } \\
\text { composite }\end{array}$ & $\begin{array}{l}\text { facile self-assembly } \\
\text { process }\end{array}$ & $\begin{array}{l}\text { two-dimensional } \\
\text { structure }\end{array}$ & $75.3 \%$ & $\begin{array}{c}1000 \mathrm{~mA} \mathrm{~h} \mathrm{~g}^{-1} \text { after } 300 \text { cycles } \\
\text { at } 2 \mathrm{~A} \mathrm{~g}^{-1}\end{array}$ & 50 \\
\hline $\begin{array}{c}\text { Nitrogen-doped Carbon Coated } \\
\text { Porous Silicon }\end{array}$ & $\begin{array}{l}\text { Reflux method and } \\
\text { carbonization }\end{array}$ & $\begin{array}{l}\text { Coating on } \mathrm{Si} \\
\text { particles }\end{array}$ & $84 \%$ & $\begin{array}{c}1904 \mathrm{mAh} \mathrm{g}^{-1} \text { After } 100 \text { cycles } \\
\text { at } 0.8 \mathrm{~mA} \mathrm{~g}^{-1}(82 \%)\end{array}$ & 51 \\
\hline $\begin{array}{l}\text { Porous nitrogen-doped carbon- } \\
\text { coated nano-silicon/graphite }\end{array}$ & $\begin{array}{l}\text { liquid-phase stirring, } \\
\text { high-temperature } \\
\text { calcination, and acid } \\
\text { etching }\end{array}$ & $\begin{array}{l}\text { Coated Si distributed } \\
\text { on graphene frame } \\
\text { work }\end{array}$ & $62 \%$ & $\begin{array}{c}622 \mathrm{mAh} \mathrm{g}^{-1} \text { after } 240 \text { cycles at } \\
500 \mathrm{mAg}^{-1}\end{array}$ & 52 \\
\hline $\begin{array}{c}\text { Nano Silicon Composite with } \\
\text { gelatin/melamine derived N-doped } \\
\text { Carbon (This work) }\end{array}$ & $\begin{array}{l}\text { Surface modification and } \\
\text { carbonization }\end{array}$ & $\begin{array}{l}\text { Surface coating on } \mathrm{Si} \\
\text { nanoparticles }\end{array}$ & $72 \%$ & $\begin{array}{c}2175 \mathrm{mAh} \mathrm{g}^{-1} \text { after } 50 \text { cycles at } \\
200 \mathrm{mAg}^{-1}(86 \%)\end{array}$ & \\
\hline
\end{tabular}

uniformly coated with an N-doped carbon matrix. When studied as an anode material for Li-ion batteries, the composite delivered excellent electrochemical properties, which can be credited to the collective effect of high-capacity Si nanoparticles with highly conductive and structurally stable carbon matrices. The N-doping also improved the conductivity of the composite and provided more ionic channels for $\mathrm{Li}^{+}$diffusion. After 50 cycles, the composite delivered $2175 \mathrm{mAh} \mathrm{g}^{-1}$ capacity with $86 \%$ capacity retention. Along with superior rate capability, the composite exhibited better diffusion properties compared with pristine $\mathrm{Si}$ particles. This study provides insight into cost-effective and eco-friendly carbon sources for carbon coatings/ composite for Si-based anode materials suitable for largescale production for $\mathrm{Li}^{+}$energy storage applications.

\section{ACKNOWLEDGEMENT}

This work was supported by the National Research Foundation of Korea (NRF) grant funded by the Ministry of Education (NRF-2018R1D1A1B07044026).

\section{CONFLICTS OF INTEREST}

The authors declare no conflict of interest.

\section{REFERENCES}

1. X. Huang, J. Yang, S. Mao, J. Chang, P. B. Hallac, C. R. Fell, B. Metz, J. Jiang, P. T. Hurley, and J. Chen, Adv. Mater. 26, 4326 (2014).

2. H. Li, Z. X. Wang, L. Q. Chen, and X. Huang. Adv. Mater. 
21, 4593 (2009).

3. F. Cheng, J. Liang, Z. Tao, and J. Chen, Adv. Mater. 23, 1695 (2011).

4. D. Han, I. Park, M. Kim, D. Kim, and H. Jung, Korean J. Met. Mater. 57, 360 (2019).

5. H. Jia, P. Gao, J. Yang, J. Wang, Y. Nuli, and Z. Yang, $A d v$. Energy Mater. 1, 1036 (2011).

6. T. Song, J. Xia, J. H. Lee, D. H. Lee, M. S. Kwon, J. M. Choi, J. Wu, S. K. Doo, H. Chang, W. I. Park, D. S. Zang, H. Kim, Y. Huang, K. C. Hwang, J. A. Rogers, and U. Paik, Nano Lett. 10, 1710 (2010).

7. P. Poizot, S. Laruelle, S. Grugeon, L. Dupont, and J.M. Tarascon. Nature 407, 496 (2000).

8. L.Y. Beaulieu, K.W. Eberman, R.L. Turner, L.J. Krause, and J.R. Dahn, Electrochem. Solid-State Lett. 4, A137, (2001).

9. M. L. Terranova, S. Orlanducci, E. Tamburri, V. Guglielmotti, and M. Rossi, J. Power Sources. 246, 167 (2014).

10. Q. Xiao, Q. Zhang, Y. Fan, X. Wang, and R. A. Susantyoko, Energy Environ. Sci. 7, 2261 (2014).

11. J.H. Park, Y.-S. Choi, H. C. Shim, J.-P. Ahn, and J.-C. Lee, Korean J. Met. Mater. 57, 67 (2019).

12. E. Radvanyi, W. Porcher, E. D. Vito, A. Montani, S. Franger, and S. J. S. Larbi, Phys. Chem. Chem. Phys. 16, 17142 (2014).

13. L. Yang, H. S. Chen, H. Jiang, Y. J. Wei, W. L. Song

14. , and D. N. Fang, Chem.Commun., 54, 3997 (2018).

15. M. S. Choi, A. Mirzaei, J. H. Bang, H. G. Na, C. Jin, W. Oum, S. Han, S. S. Kim, and H. W. Kim, Korean J. Met. Mater. 57, 732 (2019).

16. C. K. Chan, H. Peng, G. Liu, K. Mcllwrath, X. F. Zhang, R. A. Huggins, and Y. Cui, Nat. Nanotechnol. 3, 32 (2008).

17. M. R. Zamfir, H. T. Nguyen, E. Moyen, Y. H. Lee, and D. Pribat, J. Mater. Chem. A. 1, 9566 (2013).

18. J. R. Szczech and S. Jin, Energy Environ. Sci. 4, 56 (2011).

19. L. Pan, H. Wang, D. Gao, S. Chen, L. Tan, and L. Li, Chem.Commun. 50, 5878 (2014).

20. A. Nulu, V. Nulu, and K. Y. Sohn, Korean J. Chem. Eng. 37, 1795 (2020).

21. M. K. Kim, W. H. Shin, and H. M. Jeong, Appl. Surf. Sci. 467, 926 (2019).

22. T. Zhang, L. Fu, J. Gao, L. Yang, Y. Wu, and H. Wu, Pure Appl. Chem. 78, 1889 (2006).

23. X. Li, G. Zhang, L. Zhang, M. Zhong, and X. Yuan, Int. J. Electrochem. Sci, 10, 2802 (2015).
24. Y. Jiang, S. Chen, D. Mu, B. Wu, Q. Liu, Z. Zhao, and F. Wu, J. Mater. Sci. 52, 10950 (2017).

25. L. Y. Yang, H. Z. Li, J. Liu, Z. Q. Sun, S. S. Tang, and M. Le, Sci. Rep. 5, 1 (2015).

26. K. B. Djagny, Z. Wang, and S. Xu, Cri. Rev. Food Sci. Nutr. 41, 481 (2001).

27. M. Ulfa, W.Trisunaryanti, I. I.Falah, I.Kartini, and Sutarno, IOSR JAC. 7, 01 (2014).

28. X. He, W. Zhao, D. Li, P. Cai, Q. Zhuang, and Z. Ju. New J. Chem., 43, 18220 (2019).

29. Y. Gao, X. Qiu, X. Wang, X. Chen, A. Gu, and Z. Yu, Nanotechnology. 31, 155702 (2020).

30. H. N. T. Le and H. K. Jeong, New Phys. Sae Mulli. 65, 86 (2015).

31. C. C. Nguyen, D. M. Seo, K. W. D. K. Chandrasiri, and Brett L. Lucht, Langmuir. 33, 9254 (2017).

32. S. C. Feifel and F. Lisdat, J. Nanobiotechnol. 9, 59 (2011).

33. C. C. Nguyen, T. Yoon, D. M. Seo, P. Guduru, and B. L. Lucht, ACS. Appl. Mater. Interfaces. 8, 12211 (2016).

34. K. W. D. K. Chandrasiri, C. C. Nguyen, B. S. Parimalam, S Jurng, and B. L. Lucht, J. Electrochem. Soc.165, A1991 (2018).

35. A. Nulu, V. Nulu, and K. Y. Sohn, ChemElectroChem. 7, 4055 (2020).

36. A. Nulu, V. Nulu, and K. Y. Sohn, Sci. Adv. Mater. 12, 337 (2020).

37. D. Shen, C. Huang, L. Gan, J. Liu, Z. Gong, and M. Long, ACS Appl. Mater. Interfaces. 109, 7946 (2018).

38. Y. Gao, X. Qiu, X. Wang, X. Chen, A. Gu, and Z. Yu, Nanotechnology. 31, 155702 (2020).

39. A. Nulu, V. Nulu, and K. Y. Sohn, ChemElectroChem. 8, 1259 (2021).

40. M. Zhou, T. Cai, F. Pu, H. Chen, Z. Wang, H. Zhang, and S. Guan, ACS Appl. Mater. Interfaces. 5, 3449 (2013).

41. Y. Ma, G. Ji, B. Ding, and J. Y. Lee, J. Mater. Chem. A. 1,13625 (2013).

42. X. Zhou, Y. Yu, J. Yang, H. Wang, M. Jia, and J. Tang, ChemElectroChem. 6, 2056 (2019).

43. Y. S. Lee and K. S. Ryu, Sci. Rep. 7, 16617 (2017).

44. W. Wang, Z. Favors, C. Li, C. Liu, R. Ye, C. Fu, K. Bozhilov, J. Guo, M. Ozkan, and C. S. Ozkan, Sci. Rep. 7, 44838 (2017).

45. L. Zhang, R. Rajagopalan, H. Guo, X, Hu, S. Dou, and H. Liu, Adv. Funct. Mater. 26, 440 (2016).

46. H. Su, A. A. Barragan, L. Geng, D. Long, L. Ling, K. N. Bozhilov, L. Mangolini, and J. Guo, Angew. Chem. Int. Ed. 
56, 10780 (2017).

47. J. Tang, A. D. Dysart, D. H. Kim, R. Saraswat, G. M.Shaver and V. G. Pol, Electrochim. Acta, 247, 626 (2017).

48. N. Kobayashi, Y. Inden, and M. Endo, J. Power Sources, 326, 235 (2016).

49. J. S. Kim, R. Kohler, W. Pfleging, H. J. Seifert, D. Byun, H.G. Jung, and J. K. Lee, J. Power Sources, 279, 13 (2015).

50. H. M. Jeong, S. Y. Lee, W. H. Shin, J. H. Kwon, A. Shakoor, T. H. Hwang, S. Y. Kim, B. S. Kong, J. S. Seo, Y. M. Lee, J.
K. Kang, and J. W. Choi, RSC Advances, 2, 4311 (2012).

51. T. Mu, P. Zuo, S. Lou, Q. Pan, Q. Li, C. Du, Y. Gao, X. Cheng, Y. Ma, and G. Yin. Chemical Engineering Journal, 341, 37 (2018).

52. M. G. Jeong, M. Islam, H. L. Du, Y. S Lee, H. H. Sun, W. Choi, J. K. Lee, K. Y. Chung, and H. G. Jung, Electrochimica Acta. 209, 299 (2016).

53. X. Chen, Y. Xie, X. Xiong, and K. Han, Ionics 27, 1013 (2021). 